\title{
Conversation Analysis -- A Discourse Approach to Teaching Oral English Skills
}

\author{
Yan $\mathrm{Wu}^{1}$ \\ ${ }^{1}$ College of Foreign Languages, Hebei United University, Tangshan city, Hebei province, China \\ Correspondence: Yan Wu, College of Foreign Languages, Hebei United University, No. 46 West Xinhua Road, \\ Tangshan city, Hebei province, China. Tel: 86-139-3155-3695. E-mail: helenawuyan@126.com
}

Received: March 18, 2013

Accepted: April 12, $2013 \quad$ Online Published: April 26, 2013

doi:10.5539/ies.v6n5p87

URL: http://dx.doi.org/10.5539/ies.v6n5p87

\begin{abstract}
This paper explores a pedagocial approach to teaching oral English---Conversation Analysis. First, features of spoken language is described in comparison to written language. Second, Conversation Analysis theory is elaborated in terms of adjacency pairs, turn-taking, repairs, sequences, openings and closings, and feedback. Third, under the theoretical framework of Conversation Analysis, a syllabus for improving learners' oral English skills is designed in consideration to learner profile, needs analysis and communicative events and materials employed in teaching. And a teaching model is explored with reference to Riggenbach(1999). Finally, two types of assessment are discussed to provide insights for teachers on the effect of teaching and learning. All the issues discussed above will provide teachers and scholars with a clear instruction on how to apply conversation analysis to teaching oral English skills and the discussion will lead to the feasibility of applying a converstion analysis approach to teaching learners' oral English skills.
\end{abstract}

Keywords: conversation analysis, syllabus desgin, assessment

\section{Introducation}

Oral language teaching demands a variety of concerns, such as the features of spoken language compared with written language. People learn language primarily for communication with others. The participants in communication involve speakers and hearers. Therefore, we cannot speak without the consideration of the hearers. Moreover, communication happens in social life and it takes place in a certain situation, like coffee bar, office or classroom, and inside a certain culture. Therefore, we cannot speak without the consideration of the social and cultural context. Then, how should oral language skills be taught with regard to the social and cultural context? In contrast to traditional way of teaching oral English, discourse analysis provides a new window on teaching and learning oral language. It focuses on "the skills needed to put the knowledge into action and to achieve successful communication." (Cook, 1989, viii) This paper takes a perspective of conversation analysis within the field of discourse analysis, attempting to explore the ways of applying discourse analysis to classroom teaching and the effectiveness of fostering oral English skills.

\section{Features of Spoken Language}

While we are teaching spoken language, we know that we should adopt different approaches to teaching. However, we should bear in mind about the differences and similarities between spoken and written language, so that we can make informed decisions on planning teaching class.

As to the similarities and differences between spoken and written language, systemic functional linguistics has provided a systemic description (Burns, Joyce \& Gollin, 1996, p. 2). From a systemic functional perspective, language consists of a set of choices from which language users make choices and make sense. Therefore, spoken language and written language share the same language system. Nevertheless, they differ in lexicogrammatical choices in terms of the situational and cultural context embedded in language. By employing the language continuum (Burns, Joyce \& Gollin, 1996, p. 50), we can see that spoken language is more context-depended. Joyce and Gollins (1996, pp.53-58) find out two characteristics of spoken language, namely "grammatical intricacy" and "lexical density". By 'grammatical intricacy', they indicate that spoken language consists of incomplete sentences, contrast to the complete sentences in written language. By 'lexical density', they indicate that spoken language includes less content words, such as nouns. 
The similarities and differences between spoken language and written language can serve as foundation for language teaching as well as learning.

\section{Discourse Analysis and Conversation Analysis}

\subsection{A Brief Overview on Discourse Analysis}

While most sentence linguists are concerned with the formal forms of language, Zelling Harris (Harris, 1952, cited in McCathy, 2002, p.5; Cook, 1989, p. 13) wrote an article titled 'Discourse Analysis', in which he initiated to explore the 'grammatical rules' that account for the relations between the text and the social settings. Hence many researchers began to voice in this field. It involves many disciplines: "semiotics and French structuralist approach to the study of narrative" (McCathy, 2002, p.5) from the perspective of sociology; the speech act theory, conversational maxims (Austin, 1962; Searle, 1969, Grice, 1975, cited in McCarthy, 2002, p. 5) and pragmatics (see Levinson, 1983, Leech, 1983, cited in McCarthy, 2002, p. 6) from the perspective of psychology. Though discourse analysis appeals to many disciplines, it achieves at an agreement on the description of language in use.

\subsection{Discourse Analysis}

Here, Guy Cook's (1989) definition of discourse analysis has been employed: "Discourse analysis examines how stretches of language, considered in their full textual, social and psychological context, become meaningful and unified for their users." (viii) In other words, discourse analysis describes the interrelationships between language and its context (McCarthy, 2002, p.5). It differs from traditional approaches to teaching. Traditional teaching mainly concerns on the study of words, pronunciation and grammar, thinking language is independent from outside context. However, discourse analysis is concerned with the relationships between language and its context. Moreover, "discourse analysts consider context to be of primary importance". (Schiffrin, 1994; Duranti and Goodwin, 1992, cited in Riggenbach, 1999, p.2) Nevertheless, discourse analysis can not be separate from traditional teaching. As is said by Cook (1989, viii), discourse analysis takes traditional teaching of vocabulary, pronunciation and grammar as the basis of foreign language knowledge, and attends on how to apply the knowledge into practice and succeed in social communication. Thus discourse analysis relates language forms to function that a piece of discourse fulfills.

\section{A Pedagogical Approach to Teaching Oral English Skills}

\subsection{An Introduction to Conversation Analysis}

American discourse analysts primarily take a point of view of conversation analysis influenced by ethnomethodological tradition (McCarthy, 2002, p. 6). Conversation analysts initiate the study from the describable smallest units of conversation, examining the organization of the conversation. Here, conversation is not restricted to casual and informal talk, but it also includes "all forms of talk in interaction" (Schegloff, Koshik, Jacoby \& Olsher, 2002, p. 3), such as talks in educational environment, in workplace or in classroom. It concerns about the macro-level features of discourse, including "power, value systems, prestige and status" (Riggenbach, 1999, p. 23); and the micro-level features of discourse, including falling or rising intonation, stressed or unstressed syllabus, grammatical structures (ibid, p. 23).

The organization of conversation involves many aspects such as "turn taking", "turn organization", "action formation", "sequencing", "repair", "word/usage selection", "recipient design" and "overall organization of the occasion of interaction" (Schegolff, Koshik, Jacoby \& Olsher, 2002, pp. 4-5). Therefore, CA is of much importance in fostering learners' sociolinguistic competence, linguistic competence, discourse competence and strategic competence.

\subsection{Conversation Analysis}

Adjacency pairs. Adjacency pairs refer to "the pairs of utterances in talk, [which are] often mutually dependent" (McCarthy, 2002, p. 119), for example, greeting-greeting, congratulation-tanks. Usually, there are two types of responses: a preferred response and a dispreferred response (Cook, 1989, pp. 53-54). A disprefered response is often indicated by "a slight pause, or by a preface like 'Well' or 'you see', or by an explanation and justification of the response." (Cook, 1989, p.54) Moreover, the structures of adjacency pairs vary from culture to culture, and are affected by social settings, such as role relationships, situation, etc (McCarthy, 2002, p. 121).

Turn-taking. Turn-taking observes "when and how people take turns in conversation." (Burns, Joyce \& Gollin, 1996, p. 18). It is concerned with the way in which participants in interaction hold turns, pass turns, get in and get out of a talk. The point at which people alter turns is called Transition Relevance Place (TPR) (Yule 2000, p. 72). Usually, there are certain linguistic or paralinguistic devices that people can adopt to take turns. These 
devices include: overlaps, pauses, eye-contact or body gestures. Sometimes, people who do not want to take turns, may use backchannel responses, such as, $\mathrm{mm}$, yeah, right, really, to indicate that they have no desire to take turns(McCarthy, 2002, p. 27). Turn-taking may also vary in terms of socio-cultural factors.

Repairs. Participants in interaction can make corrections through repair either on their own initiative (self-repair) or be required by the other participants (other-repair) (Cook, 1989, p. 55).

Sequences. Among the three types of sequences: side sequences, insertion sequences and pre-sequences. Pre-sequences are of primary concern in sequencing, because they are frequently used by people in interaction. And it is a useful strategy to show politeness (Yule, 2000, p. 67-68). Pre-sequences occur when participants intend to "draw attention to, or prepare ground for the turn they are going to take next." (Cook, 1989, p. 56)

Feedback. Participants involved in conversation have to give some feedback to the speaker to show that they are interested in what the speaker is talking. We can employ some paralinguistic devices, such as nodding, facial expression, etc; what's more, we can use some backchannels, such as "yeah", "really?".

Openings and closings. Openings and closings are the words people used to initiate or end a conversation. They vary in terms of different speech community.

\subsection{The Value of Conversation Analysis in Teaching Oral Skills}

By investigating the transcriptions of native or non-native speakers' spoken data, learners can learn how to organize a conversation appropriately with regards to the socio-cultural factors, hence foster the sociolinguistic competence.

By investigating the sequences of a conversation, learners can learn how to co-construct a coherent discourse that functions hence foster their discourse competence.

By examining the aspects of organizing a conversation, learners can learn how to make choices from target language resources to speak accurately, hence foster their linguistic (or grammatical) competence.

By examining the way people take turns, hold turns, respond, open and close a conversation, learners are able to communicate effectively, hence develop their strategic competence.

\section{Syllabus Design}

In order to decide what should be taught in spoken English class, several factors should be taken into account, teaching context, learner profile and needs analysis.

As to teaching context, Burns and Joyce (1997, p. 78) classify it into two types, one is the context where syllabus is pre-determined and the other is where teachers are responsible for the teaching content and materials. With regards to the teaching context teachers can find out to what extent they can make decisions on the content and materials of the spoken course. Under the non-determined teaching context, teachers can work out the syllabus based on learner profile, needs analysis and communicative events.

\subsection{Learner Profile}

One of the key issue to be concerned in building learner profile is the oral English levels of learners, whether their oral English are at the beginning, intermediate or advanced level (Burns, Joyce \& Gollin, 1996, .71 ). Besides, the educational background and the access to spoken English (or language environment) should be taken into account. The data of learner profile can be collected by conducting an one-to-one interview or an small-group interview according to the size of learners. Or it can be done in the form of questionnaire.

\subsection{Needs Analysis}

Needs analysis is of much importance to the syllabus design. Through needs analysis, the teacher can find out the lacks, wants and needs of the participants. And the teacher can set the aims and objectives of the oral English courses accordingly. The way to conduct needs analysis can be done in the form of questionnaire or interview. Besides, the teacher can examine the oral English levels of the participants in the way of a proficiency assessment.

\subsection{Communicative Events}

After the aim and objectives of the spoken course has been fixed, the next step is to work out the content of the course. In referencing to Burns, Joyce and Gollin (1996, pp.73-82), the first step in deciding the teaching content is to selecting a starting point. They think that there are two starting points: starting with topics and starting with events. Burn and Joyce (1997) found that "a topic approach to content is widely accepted in all areas of education, and in language teaching it is often adopted where the needs of students or the focus of a course are 
quite broad". (p. 72) In contrast to the topic approach, "[texts approach] is often used when an overall context for language learning has been defined, such as in a specific workplace, or a university or other further study context." (ibid, p.73) Therefore, the starting point has a direct relation to the focus of this course, whether it is a narrow-focused or broad-focused course. After the starting point of teaching has been decided, teachers can develop the unit of work by employing the communicative network. If a topic approach has adopted, the steps to develop the unit of work are as follows:

Selecting a topic $\rightarrow$ Relating to real world tasks $\rightarrow$ Recording spoken discourse interaction $\rightarrow$ Identifying the particular text/ type $\rightarrow$ Designing classroom tasks $\rightarrow$ Practicing in real world situations ( adapted from Hood, 1989, cited in Burns, Joyce \& Gollin, 1996, p. 79)

If a text approach is adopted, the steps for planning a text-based course are as follows:

Finding the text $\rightarrow$ identifying the text $\rightarrow$ finding the related texts $\rightarrow$ recording spoken interactions $\rightarrow$ setting classroom tasks $\rightarrow$ practicing in real world situations ( adapted from Hood, 1989, cited in Burns, Joyce \& Gollin, 1996, p. 80)

\section{The Importance of Using Authentic Materials}

Discourse analysis highlights the importance of using authentic materials. Just as Riggenbach(1999) said,

[A] uthenticity of text is essential for insight into actual language use. Rather than created examples of sentences and structures by introspective methods, most language researchers interested in discourse use 'real data' — talk, audiotaped or videotaped, or writing'. (p. 5)

Authentic materials for two reasons. Firstly, scripted materials differ in some aspects from authentic materials. Fragmented utterances, meaning negotiation, backchannels, overlaps, hesitations, lexical choices which are often frequent in real-life communication are rare to see in scripted materials (Burns, Joyce, \& Gollin, 1996, p. 48). English learners, who are always exposed to scripted texts, are hardly able to put what they have learnt in classroom to the real language situation. $\checkmark$ However, it is true that, scripted materials may be helpful to the learners at a certain stages of learning. ( Burns, Joyce \& Gollin, 1996, p. 43) Secondly, by involving the learners in listening and analyzing authentic spoken discourse, learners are no longer the receiver of the knowledge coming from the experts, but the 'researchers' ( Riggenbach, 1999, p. 3). Thus, the motivation of language learners may be stimulated. They are more willing to take part in the activities targeted the real-life communication.

\section{Teaching Practice}

Conversation analysis activities are built on the use of the authentic materials get from people's interaction. How should the activities be organized in classroom teaching? Riggenbach (1999, p.63) has explored stages in planning conversation analysis activities. First of all, the teacher should set the objective or the purposes of the activity. And then the teacher should provide some information about the target structure. Next, the teacher can plan the activities in six steps:

Step 1: predict learners are required to make predications about the target structure. One way to undertake this is to lead the learners think about the possible similarities and differences between the target structure and the structure within their native language.

Step 2: plan learners set up a research plan that will produce samples of the target structure.

Step 3: collect data learners observe and/ or record the target structure in its discourse environment

Step 4: analyze learners analyze the data and explain results/make conclusions

Step 5: generate learners discuss the target structure or produce the target structure in its appropriate context

Step 6: review learners summarize their findings or reanalyze the data that they produced, asking whether the data conform to their conclusions in step 4. (adapted from Riggenbach, 1999, p. 63)

In Riggenbach's (ibid, p.63) model, learners are involved in discourse activities both as researchers and learners. Teachers play as a co-researcher and facilitator. However, we should be careful in applying this model in teaching practice. We should think a few factors that may constrain the development of the discourse activity. Firstly, we should consider the access to the authentic data. To what extent, learners can get the authentic data? Is it an easy or difficult task for the learners to do? Riggenbach (1999, p. 69) suggested that experts and people who have ever lived abroad can serve as the subjects if there is a lack of authentic data. But also experts and people who have lived abroad are also not easy access. Secondly, the learners' English level should be taken into 
account. However, the way of ongoing scaffolding in teaching may be a good way to solve these two problems. Burns, Joyce and Gollin (1996, p. 88) maintained that as the input of teaching is deducing the output of the learners' is increasing. Therefore, teachers can make decisions on the extent to which they should help the learners during the carrying out of discourse analysis

\section{Assessment}

Two types of assessment can be adopted in teaching: summative and formative assessment. Formative assessment can be adopted throughout the course, in the purpose of examining learners' progress and teaching effectiveness. Summative assessment can be adopted at the end of the course in the purpose of examining the final achievements of learners. Usually, learners' performances are the subjects of assessing.

There are some principles in assessing. Those are assessment criteria, method, reliability, validity and reports (Burns, Joyce \& Gollin, 1996, p. 91). Teachers should explain the criteria, method of assessment to learners and teachers should take some measures to ensure the reliability of assessment (ibid, 91). Burns, Joyce and Gollin (ibid, p.91) believe that reliability can be ensured by keeping the consistency of assessment. And they think that there are two ways to deal with it: one is to ensure 'intra-rater reliability' which means that "the same assessor should rate several task performances at the same standard" (ibid, p. 92); the other is to ensure "inter-rater reliability", which means that "several assessors should reach agreement about the same task performance". (ibid, p. 91) The validity of assessment refers to the content of assessment should in correspondence with what is claimed to be assessed (ibid, p. 92). Finally, the statements of achievements should be reported in common language (ibid, p. 92)

\section{References}

Burns, A., \& Joyce, H. (1997). Focus on speaking. Sydney: National Center for English Language Teaching and Research, Macquaire University.

Burns, A., Joyce, H., \& Gollin, S. (1996). I see what you mean: Using spoken discourse in the classroom. Sydney: National Center for English Language Teaching and Research, Macquaire University.

Celce-Murcia, M., \& Olshtain, E. (2000). Discourse and context in language teaching. Cambridge: Cambridge University Press.

Cook, G. (1989). Discourse. Oxford: Oxford University Press.

McCarthy, M. (2002). Discourse analysis for language teachers. Shanghai: Shanghai Foreign Language Education Press.

Riggenbach, H. (1999). Discourse analysis in the language classroom. Volume 1. The spoken language. Ann Arbor: University of Michigan Press.

Schegloff, E. A., Koshik, I., Jacoby, S., \& Olsher, D. (2002). Conversation analysis and applied linguistics. Annual Review of Applied Linguistics, 22, 3-31. http://dx.doi.org/10.1017/S0267190502000016

Yule. (2000). Pragmatics. Shanghai: Shangshi Foreign Language Education Press. 